\begin{tabular}{|c|c|c|}
\hline Received 27.08.2021 & \multirow{3}{*}{ Research Article } & \multirow{3}{*}{$\begin{array}{c}\text { JOTS } \\
6 / 1 \\
2022: 21-38\end{array}$} \\
\hline Accepted 22.09.2021 & & \\
\hline " Published 01.01.2022 & & \\
\hline
\end{tabular}

\title{
Eski Türklerden Günümüze Altay Şamanizminde Çök/Sök Ayini
}

\author{
Č̈k/Sök Ritual in Altaic Shamanism from Ancient Turks to Present Day
}

\author{
Nükhet OKUTAN DAVLETOV* \\ Cappadocia University (Nevşehir / Turkey) \\ E-mail:nukhetdavletov@gmail.com \\ Timur B. DAVLETOV* \\ International Organization of Turkic Culture (TÜRKSOY) \\ (Ankara/Turkey) \\ E-mail: aronxakas@yahoo.com
}

The word čök which has only been found in Tepsey VI, Tuba II and one inscription from Adrianov's collection, and has been interpreted differently by Turcologists such as Malov, Kyzlasov, Klyashtorny, Erdal, Orkun, Barutcu-Özönder and Aydın. In this study, the word čök identified in the Turkic runic texts of Siberia, and the associated ritual of libation have been evaluated as an ancient and common element in the Shamanism of Altaic peoples for the first time in Turcology. For this reason, traces of the concept have been searched in Tungus-Manchu, Korean and Mongolian as well as Turkic languages belonging to the Altaic language family. It has been emphasized that this word, which was recorded in different forms among Turkic and Mongolic peoples, can be an old and common Altaic word. In this way, the existence of Shamanism among the ancient Turks living in the Yenisei region has been exemplified with this word, and it's been seen that this concept has been preserved until the 21st century in societies speaking Turkic, Mongolic and Manchu-Tungusic languages and perpetuating traditional Shamanism. And results of this research have been presented to the service of Turcology.

Key Words: Turkic, Altaic, Shamanism, Yenisei inscriptions, libation, čök/sök.

\footnotetext{
* ORCID ID: 0000-0001-9312-8385.

* ORCID ID: 0000-0002-7767-4797.
} 


\section{J(৫)}

\section{Giriş}

Güney Sibirya'da bulunan ve Yenisey yazıtları olarak adlandırılan Türk runik metinleri, epitaf yani mezar yazıtı türünün özgün örneklerini temsil etmelerinin yanı sıra Aydın'ın ifadesiyle "Sayan-Altay bölgesi halklarının söz varlı̆ında bulunan ancak diğer bölge yazıtlarında tanıklanmayan sözcükler” (2013b: 38) içermeleri bakımından da önemlidir. Bunların biri de şimdiye dek yalnız üç yazıtta (Tuba II, Tepsey VI, Adrianov koleksiyonundan bir yazıt) tespit edilebilmiş ve farklı anlamlar yüklenmiş olan çök kelimesidir. Örneğin, E 36

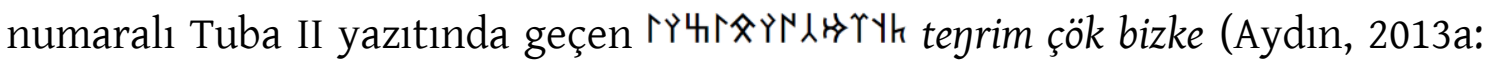
100) ${ }^{1}$ ifadesindeki çök kelimesi, Radloff tarafından "Bilinmeyen bir kelime, belki de diz çökmek, yalvarmak anlamındaki çök ile alakah olabilir" şeklinde açıklanmış ve ifadenin tamamı ise "Muhtemelen şu anlama gelir" notuyla, "Göğüm bize merhamet et” şeklinde çevrilmiştir (1985: 372). Çalışmalarında sıklıkla Eski Türklerdeki Maniheizm üzerinde duran Kızlasov ise aynı ifadeyi Hristiyanlıkta İsa'nın göklerden halka doğru inmesiyle bir analoji kurarak 'moy boje, snizoydi do nas!' [Tanrım, bize gelin!] şeklinde çevirmiştir (2001: 246-247). Malov ise ilgili yazıttaki bu kelimeyi çök yerine öçük² 'çatı' olarak okumuş ve tam ifadeyi tenrim öçük bizke 'nebo moe (bojestvo) krışa nam' [Göğüm/tanrım bize çatıdır] biçiminde vermiştir (1952: 66).

Kızlasov, kelimenin geçtiği diğer metinlerden E 116 numaralı Tepsey VI ve 1904 yılına ait Adrinanov koleksiyonundan bir metindeki ilgili ifadeleri de Tuba II'deki gibi sırasıyla tegrim çök yerk ... "moy bog snizoydi na zeml[yu]!" [Tanrım yere in!] ve tenrim çök "moy bog, snizoydi [do menya]!" [Tanrım in bana] olarak okumuştur (2001: 246-247). Aydın ise E 116 numaralı Tepsey VI'da geçen

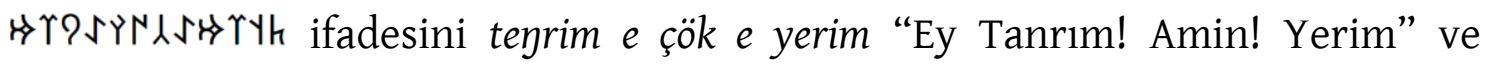
Adrianov koleksiyonundaki yazıtı da tagım a ıdok benin yalım kayam tegrikenim ${ }^{3}$ çök

1 Malov, bu runik ifadedeki bizke kelimesinin son harfini muhtemelen hatalı olarak < b > ile göstermiştir:

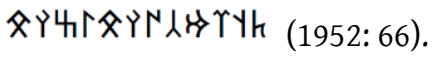

2 Aydın, Malov'un çök kelimesini öçük olarak okuyup ‘мое (божество)' [Mу [God] şeklinde çevirdiğini belirtir (Malov'dan aktaran Aydın, 2017: 13-14). Ancak Malov, öçük kelimesini değil, tegrim kelimesini 'небо мое (божество)' [Göğüm/Tanrım] olarak vermiştir. Ö̧̧ük kelimesini ise Klyaştorny gibi 'крыша' [çatı] olarak çevirmiş̧ir (Malov, 1952: 66).

3 Adrianov koleksiyonuna ait bu metin için kaynak olarak Erdal'ı gösteren Aydın, bu kelimeyi Kızlasov'un aksine tegrim değil, tegrikenim şeklinde vermiştir. Kızlasov'un kullandığı kaynak için bk. 
"dağım, kutsalım, yalçın (sarp) kayam! Azizim, amin!" şeklinde okumuştur (2013a: 208-209, 246).

Aydın, A Shamanistic Exclamation in the Yenisei Inscriptions: Çök! (2017) başlıklı çalışmasında şimdiye dek bu kelime üzerine yapılan tartışmaları ve farklı okuma denemelerini topluca vermiştir. Buna göre yukarıda görüşlerine yer verilen dilbilimcilere ek olarak Orkun, çök kelimesini 'Tanrıya karşı yapılan bir hitab' (Orkun'dan aktaran Aydın, 2017: 13-14); Barutçu-Özönder ise 'Yardım et!' (Barutçu Özönder'den aktaran Aydın, 2017: 13-14) olarak yorumlamışlardır. Bununla birlikte Erdal, çökle- fiilinin eski Uygurca metinlerde ve Drevnetyurkskiy Slovar' $\mathrm{da}^{4}$ geçtiğini belirtmekte ve Eski Uygurcada çök- köküne rastlanmasa da Tatarca ve Çuvaşça gibi bazı çağdaş Türk dillerinde kelimenin 'kurban' ve 'kurban ayini' anlamlarında kullanıldığını ifade etmektedir (1991: 434-45). Gerçekten de çök kelimesi XXI. yüzyılda basılan bir Tatarca-Rusça sözlükte dahi kendisine yer bulmakta ve 'putperestlikte ateşe kurban sunma ayini' ve 'bu ayin esnasında dile getirilen nida' olarak tanımlanmaktadır (Asılgaraev, 2007: 583). Fedotov da çök (Çuvaşça çük) kelimesini 'Pagan Çuvaşlarda kurban, kurban amaçlı sunulan yemek'; çükle- fiilini ise 'çük (kurban) sunmak' olarak tanımlamış ve bu geleneğin adının çükleme olduğunu belirtmiştir (1996: 426-427).

\section{Çuvaşlarda Çük}

Semenova, eski bir hasat bayramı olduğunu ifade ettiği çükleme kavramının Rusçaya 'kurban sunmak, şükür kurbanı sunmak' olarak çevirilebileceğini ifade ettikten sonra bu ayinin detaylarını şu şekilde aktarmıştır:

\footnotetext{
"Çuvaşlar, yeni hasattan elde edilen tahıllardan ekmek yapmadan önce bu ilk tahılların tanrılara sunulması ve bunların tüketilebilmesi için tanrılarının rızalarının alınması gerektiğine inanmaktaydılar. Kadınlar çükleme'de belirli bir yere sahipti. Örneğin ev sahibi erkeğin eşi, kocasıyla aynı sözleri ve hareketleri tekrarlar, ayinde kocasının hemen arkasından masaya otururdu. Önce masaya bir kâse yulaf lapası getirilir, lapanın ortasına bir delik açıp bu boşluğa yağ dökülür ve lapanın etrafına da kaşıklar dizilirdi. Sonra kâsenin üzerine ekmek koyulur ve ekmeğin üzerine de bir tuzluk içinde tuz yerleştirilirdi. Bazen tuz yerine peynir tercih edildiği de olurdu. Masaya büyük ağaç bir kapta bira getirilir ve ev
}

Adrianov, A. V. Pisanitsy (Otçet za 1904 g.) (rukopis) - Arhiv Muzeya arheologii i etnografii Sibiri Tomskogo gosuniversiteta, d. 55, risunki mejdu opisaniyami XIX-33 i XIX-39, XIX-36, XIX-35.

4 Otka çöklemişig yeteçiler (Nadelyayev at al., 1969: 155). 


\section{0}

sahibi tarafından ayine katılan konukların her birine bu ritüel yiyecek ve içecekten ikram edilirdi" (2015: 134-135).

Çuvaşlarda çük/çök ile ilgili bir diğer kavram da açlk havada toplu biçimde yapılan kurban ibadetini ifade eden uy çükĕ (Rodionov, 2016: 122) kavramıdır. Kelimenin Rusça kaynaklarda /ü/ yerine /u/ ile yazıldığı ve bu sebeple sıklıkla uçuk olarak geçtiği görülmektedir. Uçuk, Salmin'in ifadesiyle Çuvaşça 'vadi, ova, bozkır, tarla' gibi anlamlara gelen uy ve 'iyi bir hasat elde edebilme amaciyla ruhlara dua eşliğinde kurban sunumu' anlamındaki çuk kelimelerinden oluşmaktadır. Salmin, Çuvaşların halah uçuk'u 'halk uçuk' ve pısăk uçuk 'büyük uçuk' ifadelerinin de ayinin umumî yapısını vurguladığını belirtmektedir (1994: 35).

XIX. yüzyılın ortalarında pagan Çuvaşların Çeboksarı'daki uçuk ayinlerinden sonra hayvan kemiklerinin, yolunmuş kuş tüylerinin her yere saçılmış vaziyette bırakıldığı, Çuvaşların kurban edilen hayvanların etlerini yiyip kemiklerini yaktıkları kaydedilmiştir. Ancak kurbanın tek seferde tüketilmesi ve sunulması gerektiği için kurban etinden arta kalanların da kemiklerle beraber yakıldığı durumlar olabilmekteydi. Kurban edilen hayvanın derisi ise kiremet $^{5}$ ağaçlarına asılmaktaydı. Medvedev, günümüzde ise Başkurdistan'ın Bakalinskiy Bölgesi'ndeki Yultimirovka Köyü'nün vaftiz olmayan Çuvaşlarının, uçuk'ta kurban edilen koyun ve koçların derilerini evlerine götürdüklerini ifade etmektedir (2016: 145).

Salmin, bu törenin her yıl ya da 3 yılda bir olacak şekilde ata ruhları için düzenlenen toplu ayinlerden ve bahar ekiminden sonra yaz başında tüm köy tarafından düzenlendiğini; XIX. yüzyılın sonu ve XX. yüzyılın başlarından itibaren ise bu ayinin kötü geçen bir hasadın ardından ya da salgın hastalıklardan kurtulmak için de yapıldığını belirtmektedir (1994: 35). Uçuk bu yönüyle Güney Sibirya Türklerinden Hakasların tayı̆ dedikleri kurban törenlerini hatırlatmaktadır. Hakasların da hem bereket için hem de felaketlerden

Kiremet adı, kimi kaynaklarda Çuvaşlarda kötü ruhların yaşadığı yerin adı, kimi kaynaklarda ise doğrudan bu ruhlardan birisi olarak geçmektedir. Başta ormanlık alanlar olmak üzere, dağlarda ve su kaynaklarının yakınında kiremet adıyla anılan pek çok yer bulunmakta ve Çuvaşlar buralarda dua ve kurbanlar eşliğinde ibadet etmektedirler (Bayram, 2013: 321, 520). Kiremet kavramı için ayrıca bk. Bayram, 2015: 21-35. 
kurtulmak için iyelere köy halkı olarak dualar eşliğinde kurbanlar sundukları bilinmektedir.

\section{Güney Sibirya Türklerinde Çök/Sök}

Aydın, üç Yenisey yazıtında tespit edilen ve çök olarak okunması gerektiğini ifade ettiği bu tartışmalı Eski Türkçe kelimenin Güney Sibirya Türklerinin şaman ayinlerinde günümüzde hala kullanılması sebebiyle 'Şamanist bir nida' (2013b: 40; 2017: 17) olduğunu Altaycadan örnekler vererek ifade etmiştir. Konuyla ilgili Çarlık, Sovyetler ve Rusya Federasyonu dönemi kaynaklarında bu seslenişin ayinlerde libasyon yani saçı sırasında çıkarıldığı bilgisi verilmektedir. Ayrıca kelimeyi doğrudan şaman ayinleri ve kamlarla açıklayan Butanayev'in (1999) Hakassko-russko istoriko-etnografiçeskiy slovar adlı çalışması ve Subrakova'nın (2006) Hakassko-russkiy slovar'ı gibi daha önceki Hakasça-Rusça sözlükler de Aydın'ın bu tespitini doğrulamaktadır.

Her ne kadar uzun yıllar boyunca Altay topraklarında misyonerlik faaliyetleri için bulunan Verbitskiy tarafından 1884'te Kazan'da yayımlanan Slovar altayskago i aladagskago nareçiy tyurskago yazıka [Türk Dilinin Altay ve Aladağ ${ }^{6}$ Lehçeleri Sözlüğü] adlı sözlükte bu ifade bulunmasa da bilindiği üzere Altaylar arasında derleme yapan araştırmacıların kayıtlarında bu kelime mevcuttur. Ayrıca Verbitskiy'nin 1884 tarihli çalışmasından daha önce Rus Ortodoks Kilisesi Altay Misyonerlik Servisi üyelerince meydana getirilen ve 1869'da Kazan İmparatopluk Üniversitesi matbaasında basilan Grammatika altayskago yazıka [Altay Dili Grameri] adlı eserin 2005'te yayımlanan tıpkıbasımında da çok kelimesi 'putlara yapılan kurban saçısı esnasında çıkarılan nida' olarak tanımlanmıştır; aynı kökten türetilen çokto- fiili ise 'putlara saçı yapmak, ateşe çok nidası eşliğinde yemek parçaları sunmak' şeklinde açılanmıştır (2005: 292).

Yukarıda Çuvaşça uy çükĕ (Rodionov, 2016: 122) kavramının Rusça kaynaklarda $<\ddot{\mathrm{u}}>$ yerine $<\mathrm{u}>$ ile yazıldığ ve bu sebeple uçuk olarak geçtiği ifade edilmiştir. Aynı şekilde doğru yazımının çök olması gereken kelimenin Altaycada çok biçiminde kaydedilmiş olması da yine Rusça yazımdan kaynaklanıyor

6 Burada Aladağ Lehçesi olarak kastedilen günümüz Hakasçasıdır. Verbitskiy tarafından Altaycanın içine Teleüt, Telengit, Biysk yerlilerinin dili dâhil edilirken; Aladağ lehçesine ise Şor, Hakas ve Kuzey Biysk’te yaşayan Kumandinlerin dili dâhil edilmiştir (Verbitskiy, 1884: III-IV). 


\section{J(ఠ)}

olmalıdır. ${ }^{7}$ Nitekim İnan da kelimeyi çook olarak aktarmış ve ibadet vaktinde tekrar edilen 'Amin!' anlaminda bir kelime olduğunu ifade etmiştir (1998: 393). Ancak kelimeyi çöök şeklinde /ö/ ile veren ve Altayca 'anlatıların ve hikâyelerin sonunda kahramanları, tanrıları ya da ruhları sakinleştirmek için kullanılan kalıp bir ünlem' (Demçinova'dan aktaran Yadanova, 2013: 253) olarak açıklayan kaynaklar da bulunmaktadır. Araştırmacılar tarafından eski Türk dönemine ait Yenisey yazıtlarındaki çök ile aynı kelime olduğu tespit edilen bu çöök/çook ifadelerinin çift /ö/ ya da /o/ ile yazılmasının sebebi olarak ise kelimenin daha önce de belirtildiği üzere şaman ayinleri sırasında kaydedilmiş bir ünlem olması gösterilebilir. Nitekim alan araştırması kayıtlarına dayalı literatürde de kelimenin standart bir yazımı bulunmamaktadır.

Bu kelime, Hakasçada da söök ve seek biçiminde /s/'li olarak yaşamaktadır ve yukarıda bahsedilen diğer Türk dillerinde olduğu gibi özel bir kurban ritüeline adını vermiştir. Hakasça-Rusça sözlüklerde seek 'şarap ya da süt saçısı yapılırken söylenen nida' (Subrakova, 2006: 456); ya da söök 'Dağ iyelerine şarap veya başka içeceklerle saçı yapılırken çıkarılan ses, sesleniş’ (Butanayev, 1999: 120) olarak tanımlanmıştır. Kelimenin fiil hali olan seektirge (seekte-) Hakasçada ‘Şaman ayini sırasında içki saçmak, kurban yerlerinin iyelerine ve putlara/idollere saçı yapmak' (Subrakova, 2006: 456) ve sööktirge de 'Şarap veya tütünü dağ iyelerine saçmak' olarak yer almaktadır: Ham pozını tösterǐne sööktepçe “Kam, kendi yardımc1 ruhlarına sööklüyor/söökleme yapıyor" (Butanayev, 1999: 120). Hakasçada söök ritüeli ile ilgili bir diğer kavram da "kamlama esnasında şamana sunu maddesini getiren yardımcı kişi’ anlamına gelen sööktecen kı̌zìdir (Butanayev, 1999: 120).

İmparatorluk Rus Coğrafya Cemiyeti olarak çevirebileceğimiz İRGO ile Rusya Orta ve Doğu Asya Araştırma Komitesi tarafından 1913-1914’te araştırma yapması için görevlendirilen Stepan Maynagaşev, Hakasların XX. yüzyılda hala sürdürmekte oldukları geleneksel tiğr tayii (gök ayini) sırasında kurban sunulurken "seek-seek" ifadesinin kullanıldığını kaydetmiştir (1916: 97):

İleride bahsedilecek olan söök/seek ya da söög/seeg kelimelerinde de hem /ö/ hem /e/'li yazım dikkat çekmektedir. Bunun da Rusça yazımdan kaynaklandığını düşünmekteyiz. Araştırmacıların Kiril alfabesinde /ö/ sesini verebilmek için kullanmaları gereken <ë> yerine <e> harfini tercih etmelerinden dolayı zaman içinde kabullenilmiş bir dönüşüm söz konusu olabilir. 


\section{J(৫)}

Küger turğan kük tiğ̌r, sek!

Göğerip duran mavi gök ${ }^{8}$, sek!

Küdǐr turğan hara çir, sek!

Bizi taşıyan kara yer, sek!

Butanayev de 1972'de Kirba Dağı'nda yapılmış bir tağ tayii yani dağ iyelerine kurban sunma ayini sırasında söylenen aşağıdaki duayı, 1888 doğumlu Sıgan Domojakov'dan kaydetmiştir (2006: 161-163):

Söök! Söök!

Adap turğan tisker miis

Tipsey hayrahan!

Arğa çahsı çonnın tayii çitš̌n!
Söök! Söök!

Adını andığımız, tisker ${ }^{9}$ yüzlü

Tepsey hayrahan! ${ }^{10}$

Emekçi iyi halkın kurbanları sana ulaşsın!

Butanayev aşağıdaki duayı ise zamanında Arkut Sunçugaşev adlı 1890 doğumlu ünlü bir Hakas şamanın ayinine katılmış olan 1916 doğumlu Tatyana Domogaşeva adlı bir katılımcıdan 1980'de kaydetmiştir. Duanın başında şaman, Hakasların tös dedikleri iyeleri ve koruyucu ruhları, onlara seek nidasıyla seslenip besleyerek çă̆ırmaktadır (2006: 207-209):

Seek, seek!

Adam hannay alğan huyağımnıy eeleř̌

Azır holıma çayalıp odırınar.
Seek, seek!

Atam handan aldı̆̆ım zırhımın iyeleri

Çatal koluma yayılıp oturunuz.

Hakasların bu ritüeli günümüzde de seek-seek adıyla yaşattıkları, alan araştırmaları sırasında görülmüştür. Örneğin görüşme sırasında 40 yaşında olan Hakas Dili ve Edebiyatı öğretmeni Aleksey Çaptıkov, kendisine Erlik Han (Hakasça İlĭg) ile ilgili bir soru sorulduğunda başından geçen şu hikâyeyi anlatmıştır:

\footnotetext{
“Bir gece komşu köye gitmiştik. Dönüş yolunda yan gözle baktığımda bir de gördüm ki ileride bir atlı gecenin içinde koşturarak geliyor. Atın sadece yarısı, yani ön ayakları görünüyordu, arkası ise görünmüyordu. Beni durdurmaya çalışıyordu sanki. Ben korkup daha hızlı gitmek istedim; ama birden araba duruverdi, motor çalışmıyordu. O anda bir baktım ki arabada bir şişe içki duruyor. Çocukken duyduğum seek-seek geldi aklıma. Seekseek yapınca araba çalışıverdi. O atlının İrlĭg olup olmadığını bilmiyorum; ama sonradan
}

8 Ana dili olan Hakasçaya ve Hakas kültürü ile Hakas Şamanizmine vakıf bulunan S. D. Maynagaşev, bizzat katıldı̆̆ı tigǐr tayii esnasında okunan dualarda geçen kük (kök) tiǧ̌r ifadesini, Türk runik metinlerinde olduğu gibi doğrudan mavi gök (sinee nebo) olarak açıklamıştır.

9 Ters yön, bat1.

10 Efendi, tanri. 


\section{J(৫)}

bana anlatılana göre orası aslında şamanların yoluymuş ve biz de işte onların arasına girmişiz. Yoldan ilk geçişimizde saçı yapmamıştık, galiba o yüzden dönüşte geçmemize izin vermediler. Korkudan o şişenin hepsini orada yolda bıraktım. Yolun açık olması için içki yoksa bile ekmek gibi kişinin yanında ne varsa ruhlara bırakması gerekir" (Okutan Davletov, 2021: 73).

Söz konusu kurban geleneği, Şamanizmde köklü bir yere sahip olduğundan bu uygulama ile ilgili terimlerde hem ortaklık hem zenginlik söz konusudur. İlk olarak Türk ve Moğol halkları arasındaki Şamanizm terminolojisinin ortaklığına ya da kültürel ve dilsel etkileşime işaret etmesi bakımından 'bayramlarda putlara içki sunulacağı zaman saçılacak kurban' olarak tanımlanan Moğolca tsatsal ve 'saçmak, serpmek' anlamlarına gelen tsatsah kelimeleri (Altangerel, 2001: 340) örnek gösterilebilir. Birtalan da bu kelimenin 'tanrılara sunulan süt, sütlü çay ya da kımız libasyonu' yani saçı anlamına geldiğini ve Kalmukça ile Oyratçada da tsatsl şeklinde mevcut olduğunu, kökünün ise saču fiili olduğunu belirtmektedir (2004: 589).

Saçı kavramı dışında Hakasçadaki şu kelimeler de dikkat çekicidir: Y̌lĭg 'serpme, saçı'; çaçığ 'iyelere (dă̆, nehir vs) şarap, süt, çay saçma ritüeli'; nanı̆̆ 'şarap saçmak' (Subrakova, 2006: 144, 270, 958). Günümüzde Hakaslar tarafından sık kullanılan bu terimleri aşağıdaki dua metinlerinde görmek mümkündür. Haritonova'nın (2006: 206) T. S. Burnakova adlı bir Hakas şamandan kaydettiği dua tarafımızca Türkçeye aşağıdaki şekilde çevrilmiştir:

Ulu dağlarım, ulu nehirlerim!

Size illǐk ${ }^{11}$ yapıyorum!

Seek!

Yüce dağlarım, engin sularım!

Şaman ağacım! Size îlı̌k sunuyorum!

Hakasların köl tayii dedikleri göl iyesi için düzenlenen kurban töreninde edilen aşağıdaki dua ise Butanayev tarafından kaydedilmiştir (2003: 243). Duada çaçı̆̆ kelimesi şu şekilde geçmektedir:

Toğıs Ǐžktǐg Hara köl hayrahan!

Çitǐ tündüktǐg Hara köl hayrahan!
Dokuz kapılı Kara göl hayrahan!

Yedi tündüklü Kara göl hayrahan!

${ }^{11}$ Hakasçada kelime ilik değil, ilĭg olarak yazılmaktadır; ancak metin Rusçaya aktarılırken bu şekilde yazılmış olmalıdır. 


\section{$\mathrm{J}(\mathrm{O})$}

Ah malnıy südǐney çaçı̆̆ pirerbǐs,

Ak malın sütüyle saçı yapıyoruz,

Ah malnı soğıp, tayığ iderbǐs.

Ak malı kesip, kurban ediyoruz.

Bu noktada Tivacaya Moğolcadan geçtiği düşünülen ve 'acımak, merhamet etmek, affetmek' anlamlarına gelen örşe- fiilinden türeyip 'Ey Tanrım! Aman Tanrım!' anlamlarında kullanılan bir ünlem olan örşee $e^{12}$ (Ölmez, 2007: 235) de dikkat çekicidir. 44 yaşındaki Ernazar Kuular, kişisel görüşme sırasında günümüzde Tıva sınırları içerisindeki Tıvaların, komşuları olan Hakaslar ve Altayların aksine saçı sırasında örşee ünlemiyle kurban sunumu yapmakta oldukları bilgisini paylaşmıştır (11 Temmuz 2021). Tarafımızca yapılan taramalarda da Tıvaca sözlüklerde bu araştırmanın konusu olan çök, çöök, çook, şök, sek, seek ya da söök kelimelerine rastlanamamıştır. Tıva Cumhuriyeti Tuvalarından 44 yaşındaki Viktoriya Soyan Peemot ise yukarıdaki bilgiye ek olarak Tivalar tarafından Güney Tıva olarak nitelendirilen Moğolistan'ın Bayan Ölgiy Aymağı'ndaki Tıvaların, Altay Dağı'na ve göğe saçı yaptıkları ve kendisinin de bizzat tanıklı ettiği şaman ayinleri sırasında üç kez çöök dendiğini ifade etmiştir (11 Temmuz 2021). Literatür taraması sonucunda Buryat topraklarında yaşayan Soyotların ${ }^{13}$ da şaman ayini esnasında saçı yapılırken söylenen nida anlaminda hem şöök şöök hem de söög söög dedikleri tespit edilmiştir (Rassadin, 2003: 157; 2012: 140). Görüldüğü üzere Moğolistan Tivaları, Soyotlar ve Güney Sibirya Türkleri arasında sosyokültürel ve lengüistik bütünlükten bahsedilebilmektedir.

Güney Sibirya Türklerinden Şorların Aba (Ayl) aşiretine mensup 1978 doğumlu Çıltıs Tannagaşeva da kişisel görüşme sırasında Şorların şaman ibadetlerinde şök şök dediklerini ifade etmiştir (12 Temmuz 2021). Maynagaşev de Radloff'a dayanarak Hakaslardaki sek ya da seek kelimesinin Şorlarda şök, şok ve Teleütlerle Altaylarda ise çok şeklinde söylendiğini belirtmiştir (1916: 100). Görüldüğü üzere Güney Sibirya Türkleri arasında söz konusu saçı geleneği, XX. yüzyılın başından XXI. yüzyıla dek aynı adla devam etmektedir.

12 Moğolcada örşöö- 'affetmek, merhamet etmek' anlamlarına gelmektedir: Burkhan örşöö! 'Tanrı korusun!”. Bu fiil kökünden türeyen örşööl ise 'merhamet, kutsama, af' anlamındadır (Altangerel, 2001: 181).

13 Rassadin'e göre Soyotların konuştukları dil Tofalar, Dukhalar ve Doğu Tıvalarına yakın bir Türk dilidir (2012: 5, 153). 


\section{Buryatlarda Söög/Seeg}

Bu çalışmada ortaya koyulmak istenen esas husus ise önceki çalışmalardan farklı olarak Eski Türk yazıtlarında tespit edilen çök kelimesi ve bu kelime etrafında şekillenen söz konusu ibadetin yalnız Türk halklarında bulunmadığı, Türkler, Moğollar ve Mançu-Tunguzlar gibi Altay halkları için ortak bir kültürel ve inaçsal öge olduğu, bu sebeple VIII-IX. yüzyıllardan çok daha eskiye dayanıyor olabileceği düşüncesidir. Nitekim gerçekleştirilen literatür taraması sonucunda Moğol halklarından Buryatlarda da bu nidanın aynı anlamda kullanıldığı tespit edilmiştir. Buryatçada söög kelimesi şu şekilde açılanmaktadır: "Şamanın ayin strasinda Söög! Söög! Söög! şeklinde üç kez seslenmesi, nida. İyeye, tanriya her seslenişten sonra söylenir ve buna içki saçısı eşlik eder. Anlamı ise 'kurbanı kabul et, yakarışa kulak ver' şeklindedir" (Şagdarov \& Çeremisov, 2008: 186). Örnek olarak Okladnikov'un (1974: 19), Hangalov adlı bir Buryat araştırmacıdan aktardı̆̆ı, Baykal kıyısında bulunan Sagan Zaba [Beyaz Kaya] adlı kutsal bölgenin iyelerine yapılan şu dua gösterilebilir:

Seeg!

Altın gün anamızın ışıklarıyla,

Yuvarlak ay atamızın ışı̆̆ıyla,

Esege malan babamızın alkışıyla

Ehe Yüren anamızın alkışıla [...].

Dampilova, Moğol halklarının şaman dualarında sıklıkla ritmik yapıyı dengelediği ve hitabeti süslemeye yaradığ gibi büyüsel etki yaratan ay huray, seek/sook, şureg-şureg gibi sürekli ses tekrarlarına başvurulmakta olduğunu ifade etmiş ve örnek olarak aşağıdaki Buryat duasını vermiştir (2012: 45-46):

\footnotetext{
Seeg! Buryaad bulgad hoyor seek! Seeg! Buryat ve Bulagatlar, seek!

Seeg! Budaan mete budargahan, seek! Seeg! Saçılmış darı gibi, seek!

Seeg! Bulag mete debergehen, seek! Seeg! Dökülen pınar gibi, seek!
}

Dampilova'nın Moğol halkları için ifade ettiği ritmik yapıyı dengelemeye, hitabeti süslemeye ve büyüsel etki yaratmaya yarayan ay huray, seek/sook (Dampilova, 2012: 45) gibi sözcükler, Hakaslardaki seek ve huray nidaları ile örtüşmektedir. Nitekim XX. yüzyılın başında Sapogov köyünde yaşamış bir Hakas şaman olan Kam Pituk'un ayin başlangıcında geleneksel evin kapısına gidip eşikteki töslerin yani yardımcı ruhların çağrılması anlamına gelen tös tarthanı 


\section{J(৫)}

sırasında ettiği duada Huray huray hurayım! Söök söök söögeyim! şeklinde haykırdığ1 kaydedilmiştir (Butanayev, 2006: 201). ${ }^{14}$ Mikhailov'a göre de Moğol halklarındaki Ay hurly, huray, huruy nidalarl, erken komünal sistem dönemine kadar uzanmaktadır ve totemik-orgiastik ritüellerle ilişkilidir. Duanın başında ya da sonunda tekrarlanan bu kod yani huray, tanrılardan merhamet dilenmek için kullanılmaktadır ve tekrarlanan seeg nidası ile örtüşmektedir; çünkü her ikisinin de büyüsel bir işlevi vardır (Mikhailov'dan aktaran Dampilova, 2017: 47-48).

Dampilova'ya göre bu ayinlerde yalvarma ve kurban sunma olarak ifade edilebilecek iki ana işlev bulunmaktadır. Ayinin dua kısmı, insanın yardım isteğini ve zarar görmeme dileğini gösterirken, saçı yani kurban kısmı ise insan dünyasındaki dengeyi sürdürebilmek için gerçekleştirilmektedir (2012: 46; 2017: 48):

Khara mongol burkhandaa

Harbayn bayna ejenşni.

Söög khayrkhan, barandaa khürtegt!!
Kara Moğol'a, tanrılara

(Sunuların) sahibi hediyeler sunuyor.

Söög khayrkhan, hepsini alınız!

Baykal Gölü'nün kuzey kıyıları, Eski Çă̆ ve Orta Çağ'dan kalan petroglifler bakımından oldukça zengindir. Buryatların inanışlarına göre kayalarda ve dağlardaki bu çizimler, tanrılar tarafından yapılmıștır. Örneğin Baykal Gölü’nün Aya kayasındaki resimlerin iyesi, Tanrı Ergel Sagan Noyon, o bölgedeki köylerin ve halkın koruyucusu olarak tapınım görmektedir. Bu sebeple taylgan ${ }^{15}$ esnasında ona şöyle seslenilmektedir (Baldaev'den aktaran Daşieva, 2012: 22-23):

Seeg!

Altın yeri koruyan

Aya'nın iyesi

Resimli tanr 1

Ergel ak iye

Kutlu ak tanr!!

Ak saçlı ak hatun

14 Butanayev bu duayı, söz konusu ayinde bulunmuş olan 1889 doğumlu P. N. Kotojekov'dan 1973'te kaydetmiştir.

15 Taylgan ya da taylagan, Buryatlarda dağ, nehir, göl gibi yerlerin iyeleri için düzenlenen dua ve kurban ayinlerinin adıdır (Daşieva, 2009: 32). Kelime, Hakasçada aynı anlamdaki tayı̆̆ kelimesi ile ilişkili olmalıdır. 


\section{ग(৫)}

Bu toprakları koruyun

Yurdumuzu koruyun!

Sürülerimizi ve yılkımızı çoğaltın.

Bizi varlıklı ve mutlu kılın,

Torunlarımızı ve onların çocuklarını gösterin!

Sayımızı artırın ve bizi esen kılın!

\section{Altayca Bir Kelime Olarak Çök/Sök}

Türk runik metinlerinde tespit edilen çök kelimesi ve bu kelime etrafında şekillenen saçı ritüelinin Altay Şamanlığında ortak bir unsur olduğu ve Türk runik metinlerinin yazıldığı Orta Çağ'dan çok daha eskiye dayandırılabileceği düşüncesi yukarıda ifade edilmiştir. Bu düşünceden hareketle Türk ve Moğol halklarında çök, çöök, şök, şöö, sök, söök, söög, sek, seek ve seeg gibi farklı biçimlerde kaydedilmiş olan bu sözcügün eski ve ortak bir Altayca sözcük olabileceği ihtimali üzerinde durma gerekliliği doğmaktadır.

Kelime, yukarıda örnekleri verilmiş olan Türk dillerinde çök, çöök ve şök, şöök olarak /ç/ ve /ş/ sesi ile söylenirken Hakasçada ise Moğol dillerinden Buryatçadaki gibi söök ve seek şeklinde /s/'li olarak yaşamaktadır. Karahan, /ş/ > /s/ değişmesinin Kıpçak grubundaki bazı Türk dillerinin karakteristik özelliği olduğunu ve Kıpçakların bu ses özelliğini ilk anavatanlarındaki komşularından almış olabileceklerini belirtmiştir (2003: 41-42). Arıkoğlu'nun (2012: 25) Eski Moğolca kelime başı /s/ sesinin modern Moğolcada genelde korunmakla birlikte bazı kelimelerde /ş/'ye dönüştüğü ve bu seslerin Tıvacada da /ş/'li olduğu ifadesi de bu görüşü desteklemektedir. Örnek olarak Moğolca tsagaan kelimesi gösterilebilir. Bilindiği üzere 'ak, beyaz' anlamına gelen bu kelime Buryatçada sagaan, Tivacada şagaa, Altaycada ise çaga olarak kullanılmaktadır. Bu durumda sök-şök-çök kelimeleri üzerinden de bir /s/-/ş/-/ç/ dönüşümünden bahsetmek mümkün görünmektedir. Aydın da şad kelimesinin Uygur yazıtlarında iki kez çad olarak yazıldığını belirtmekte ve Türk runik alfabesinde /ş/ sesini gösteren işaretin /s/ sesini de karşıladığını unutmamak gerektiğini ifade ederek Eski Türkçede diyalektler üzerinde durmuştur (2018: 170-171).

Bu bilgiler bizi eski Türkçedeki 'diz çökme, itaat etme, parçalama, aşağı indirme, bir engeli aşma' (Nadelyayev at al., 1969: 510; Clauson, 1972: 819) anlamlarına gelen sök- ile Orta Türkçe metinlerde geçen aynı anlamlı çök- fiiline 
götürmektedir. Bilindiği üzere Bilge Kagan Doğu 27'de karıg söküpen 'karı sökerek'; Bilge Kagan Kuzey 10'da tizligig sökürtüm 'dizlilere diz çöktürdüm'; Bilge Kagan Doğu 3 ve 13’te ise tizligig sökürmiş 'dizliye diz çöktürmüş’ (Tekin, 2014: 46, 50, 54, 60-61) ifadeleri yer alırken kelimenin /ç/'li varyantı karşımıza çıkmamaktadır. XI. yüzyıl metinlerinden Kutadgu Bilig'de ise aynı anlamda hem çök- hem de sökfiili kullanılmaktadır. Örnek olarak 4058. beyitteki iki tiz bile sök 'iki diz üzerine çök' ve 5457. beyitte çöküp bardı egnim 'omuzlarım çöktü' ifadeleri gösterilebilir (Arat, 1947: 409, 542; 1959: 294, 391).

Starostin et al. çök- fiilini Tunguzca, Korece, Japonca, Moğolca ve Türkçe gibi akraba kabul edilen dillerde arayarak kelimenin ortak Altayca kökenine işaret etmişlerdir (2003: 450, 1305). Anadili Korece olan Dr. Juyeong Jang, modern Korecede cuk 죽 (jug, juk, cug, çuk) fiil kökünün 'ölmek', cugi- fiilinin ise ‘öldürmek' anlamlarına geldiği bilgisini paylaşmıştır (28 Ocak 2021). Dikkat çekicidir ki Hakasçada da sokh- fiilinin birinci anlamı 'dövmek' iken ikinci anlamı 'kesmek, öldürmek' olarak karşımıza çıkmaktadır (Subrakova, 2006: 485). Ayrıca Altay halklarından Tunguz-Mançuların dillerinde de biçimsel ve anlamsal olarak benzer fiillerin var olması dikkat çekicidir. Örneğin, Mançu-Tunguz dilleri için ortak kök olan ve 'baş eğmek' anlamına gelen suk'tan türeyen suka- fiili Mançucada 'bir şeyi dökmek' anlamında da kullanılmaktadır. Yine MançuTunguz dillerinde suku- 'bozmak, kırmak, parçalamak, zarar vermek, ihlal etmek' anlamlarını taşırken, suksu- fiili ise 'saçmak' anlamındadır. Aynı kökten türeyen ve Mançuca sukduhen- 'bir kurbanın ruhlar tarafından kabul edilmesi'; Negidalce sugde/sugdeçe 'kurban sunmak'; Ulçça sugdu-, sugdiçi- 'putların önünde kurban sunmak'; Orokça sugditçi- 'ölenin ruhuna yemek sunmak' (Tsintius, 1975: 118, 122) anlamlarını taşıyan sözcükler ise Altay Şamanizmindeki kurban ve saçı geleneğine işaret etmesi bakımından mühimdir.

Daha önce belirtildiği gibi Radloff (1985: 372) ve Kizlasov (2001: 246-247) Yenisey yazıtlarındaki çök kelimesini sök ile aynı doğrultuda, diz çökmek ve inmek kavramlarıyla açıklamışlardır. Bu noktada Aydın'ın Yenisey yazıtlarındaki çök kelimesinin ayinsel bir ünlem olduğu görüşüne katılmakla birlikte dinî bir eylem olan kurban töreni sırasında itaat ve yükünmenin yani diz çöküp eğilmenin söz konusu olduğunun vurgulanması gerektiği düşüncesindeyiz. Ağca da Eski Türkçe dönemindeki yükün- ve sök- fiillerinin, bedensel hareketleri gösteren 'birisinin önünde baş ile ya da bel ile eğilmek' ve 'diz ile çökmek' kaynak 
anlamlarının zamanla metaforlaşarak 'itaat etmek', 'tapınmak, ibadet etmek' anlamlarına dönüştüğünü ifade etmiştir (2021: 7-8). Ayrıca Şamanlıktaki bu kurban, saçı yöntemiyle dağıtılarak, küçük parçalara ayrılarak sunulduğuna göre Eski Türkçedeki sök- ve Mançu-Tunguz dillerindeki suk- kökünün yukarıda belirtilen parçalama, dağıtma, saçma anlamı da bağlamdan uzak görünmemektedir. Nitekim Tuvacada sögürü ${ }^{16}$ 'selamlamak, selam vermek, yaltaklanmak'; sök- ise 'sökmek, çekip çıkarmak, koparmak' (Ölmez, 2007: 253) anlamlarına gelmektedir. Moğolcada da sögdöh 'diz çökmek’ (Kruçkin, 2006: 516517), 'itaat etmek, birinin önünde diz çökmek, hürmet sunmak' (Kruçkin, 2006: 786) anlamlarındayken sögnöh 'bayramlarda veya şenliklerde şarap ya da kımız sunmak veya dökmek' (Lessing, 1960: 731) anlamına gelmektedir. Moğolistan Kazaklarından Dr. Raima Auyeskhan da sögnöh kelimesinin günümüz Moğolcasında 'içki sunmak, ikram etmek' anlamında kullanıldığı bilgisini paylaşmış ve sözlük taramasından elde edilen verileri desteklemiştir (31 Ocak 2021). Görüldüğü üzere Altay dillerinde 'eğilmek, çökmek, parçalamak, saçmak, dağıtmak, öldürmek ve kurban sunmak’ anlamlarının söz konusu fiiller için ortak olduğundan bahsetmek olanaklıdır.

\section{Sonuç}

Bu çalışmada şimdiye dek yalnız üç Yenisey bölgesi yazıtında tespit edilen çök kelimesinin ve bu kelime etrafında şekillenen saçı ritüelinin Altay halklarının Şamanizminde ortak bir unsur olduğu ve Eski Türkçe döneminden çok daha eskiye dayandırılabileceği ileri sürülmüştür. Bu doğrultuda Türk ve Moğol halklarında çök, çök, şök, şöök, sök, söök, söög, sek, seek ve seeg gibi farklı biçimlerde kaydedilmiş olan bu ünlemin eski ve ortak bir Altayca sözcük olabileceği ihtimali üzerinde durulmuştur. Özellikle Eski Türkçedeki sök- ile Mançu-Tunguz dillerindeki suk- fiillerinin anlamları ve bu fiillerle aynı adı taşıyan ayinlerin yapısı karşılaştırılarak runik metinlerdeki çök nidasının temelinde yatan esas düşüncenin, yükünülen kutsala kurban nesnesini katı ise küçük parçalara ayırarak, sıvı ise saçarak sunmak olduğu ileri sürülmüştür. Kelimenin anlamı konusunda ise Çarlık, Sovyetler ve Rusya Federasyonu dönemi kaynaklarına başvurulmuş ve bu kaynaklarda da kelimenin, ayinlerde libasyon sırasında çıkarıldı̆̆ı bilgisinin verildiği ifade edilerek Erdal ve Aydın'ın görüşleri

16 Yakutçada da suguruy 'diz çökmek, eğilmek' anlamına gelmektedir (Sevortyan, 2003: 343). 
desteklenmiş, ayrıca Radloff'un getirdiği açılamada doğruluk payı bulunabileceği ifade edilmiştir. Üretilen yeni çalışmalarla birlikte her geçen gün daha fazla ilerleme kaydedilen Türkoloji sahasında bu konudaki tartışmalar henüz sona ermemiştir. Ancak kurban sunma geleneği üzerinden Eski Türkler ile günümüz Sibirya Türkleri, Moğol halkları ve Mançu-Tunguzların da dâhil olduğu Altaylılar arasında Şamanizm bağlamında kültürel devamlılıktan söz etmek mümkün görünmektedir.

\section{Kaynak Kişiler}

Çlltıs Tannagaşeva, 12 Temmuz 2021 (Telefon Görüşmesi); Ernazar Kuular, 11 Temmuz 2021 (Telefon Görüşmesi); Juyeong Jang, 28 Ocak 2021 (Telefon Görüşmesi); Raima Auyeskhan, 31 Ocak 2021 (Telefon Görüşmesi); Viktoriya Soyan Peemot, 11 Temmuz 2021 (Telefon Görüşmesi).

\section{Kaynakça}

Ağca, F. (2021). Köl Tigin ve Bilge Kağan Yazıtlarındaki başlıgıg yüküntür - tizligig sökür - İbaresi Hakkında. Selçuk Üniversitesi Türkiyat Araştırmaları Dergisi, 52, 1-16.

Altangerel, D. (2001). Orchin Tsagiyn Mongol-Angli Tol' (A Modern Mongolian-English Dictionary). 2nd Ed. Ulaanbaatar: Interpress.

Arat, R. R. (1947). Kutadgu Bilig I Metin. İstanbul: Millî Eğitim Basımevi.

Arat, R. R. (1959). Yusuf Has Hacib, Kutadgu Bilig II Tercüme. Ankara: Türk Dil Kurumu Yayınları.

Arıkoğlu, E. (2012). Tuva Türkçesinde Moğolcadan Alınan Unsurların Ses Bilgisi Açısından Durumu. Dil Araştırmaları, 11, 17-36.

Asılgaraev, Ş. N. et al. (2007). Tatarsko-Russkiy Slovar I-II. Kazan: İzdvo Magarif.

Aydın, E. (2013a) Yenisey Yazıtları. In Ölmez, M. (Haz.), Yenisey-Kırgızistan Yazıtları ve Irk Bitig (pp. 17-277). Ankara: BilgeSu Yayınları.

Aydın, E. (2013b). Yenisey Yazıtlarındaki Tek Örnekler. Türkbilig, 26, 37-49.

Aydın, E. (2017). A Shamanistic Exclamation in the Yenisei Inscriptions: Çök! Central Asiatic Journal, 60(1/2), 13-17.

Aydın, E. (2018). Uygur Yazıtları. İstanbul: Bilge Kültür Sanat Yayınları.

Bayram, B. (2013). Ulıp Çuvaş Türklerinin Kahramanlık Destanı. Ankara: TÜRKSOY Yayınları. 


\section{0}

Bayram, B. (2015). Gyula Mészáros’un 1908 Y1lı Raporuna Göre Çuvaşlar Üzerine Tespitler. Türk Dünyası, 40, 21-35.

Birtalan, Á. (2004). Mongolian Shamanic Texts. In Walter, M. N. et al. (Eds.), Shamanism: An Encyclopedia of World Beliefs, Practices, and Culture I (pp. 586-92). Santa Barbara, CA: ABC-CLIO.

Butanayev, V. Y. (1999). Hakassko-Russko İstoriko-Etnografiçeskiy Slovar. Abakan: İzd. HGU.

Butanayev, V. Y. (2003). Burhanizm tyurkov Sayano-Altaya. Abakan: İzd-vo HGU.

Butanayev, V. Y. (2006). Traditsionny şamanizm Hongoraya. Abakan: İzd-vo HGU im N. F. Katanova.

Clauson, Sir G. (1972). An Etymological Dictionary of Pre-Thirteenth Century Turkish. Oxford: Oxford University Press.

Dampilova, L. S. (2012). Şamanskie Pesnopenie Buryat: Simvolika i Poetika. 2. Bask1. Moskva: Vostoçnaya Literatura.

Dampilova, L. S. (2017). Etnomentalnye Kody v Şamanskih Tekstah Mongolskih Narodov. In Cultural Heritage of The Mongols: Manuscript And Archival Collections. Third International Conference under the Patronage of the President of Mongolia (pp. 47-48). St. Petersburg \& Ulaanbaatar.

Daşieva, L. D. (2009). Buryatskiy Krugovoy Tanets Yohor: İstoriko-Etnografiçeskiy, Ladovy, Ritmiçeskiy Aspekty. Ulan Ude: İzd-vo BNTs SO RAN.

Daşieva, N. B. (2012). Traditsionnye Obschestvennye Prazdniki Buryat: İstoriya $i$ Tipologii. Sibir: Etnosy i kultury. Vypusk 12. Ulan Ude: İzd.-poligr.

Erdal, M. (1991). Old Turkic Word Formation: a Functional Approach to the Lexicon I-II. Wiesbaden: Harrassowitz Verlag.

Er-Tarduş (B. Y. Bedyurov). (2005). Grammatika Altayskogo Yazıka. İzd. 2-oe. Gorno Altaysk: Ak Çeçek.

Fedotov, M. R. (1996). Etimologiçeskiy Slovar Çuvaşskogo Yazıka II. Çeboksarı: Çuvaşskiy gosudarstvenny institut gumanitarnyh nauk.

Haritonova, V. İ. (2006). Feniks iz Pepla? Sibirskiy Şamanizm na rubeje tysyaçeletiy. Moskva: Nauka.

İnan, A. (1998). Türk Şamanizmi Hakkında. In Makaleler ve İncelemeler I (pp. 389396). 3. Baskı. Ankara: Türk Tarih Kurumu Yayınları. 


\section{0}

Karahan, L. (2003). Türkiye Türkçesi Ağızlarında ş > s Değişmesi ve Çalış Beldesi (Haymana) Ağzı. Selçuk Üniversitesi Türkiyat Araștırmaları Dergisi, 13, 41-62.

Kızlasov, İ. L. (2001). Smena Mirovozzreniya v Yujnoi Sibiri v Rannem Srednevekovye (İdei Yedinobojiya v Yeniseyskih Nadpisyah). Drevniye Tsivilizatsii Yevrazii. İstoriya i Kultura. Materialy Mejdunarodnoy Nauçnoy Konferentsii, Posvyaşennoy 75Letiyu Deystvitelnogo Çlena Akademii Nauk Tadjikistana, Akademika RAEN, Doktora İstoriçeskih Nauk, Professora B. A. Litvinskogo (Moskva, 14-16 oktyabrya 1998 g.) (pp. 243-270). Moskva: Vostoçnaya Literatura.

Kruçkin, Y. N. (2006). Bolşoy Sovremennıy Russko-Mongolski-Mongolsko-Russkiy Slovar. Moskva: ACT, Vostok-zapad.

Lessing, F. D. (1960). Mongolian-English Dictionary. Bloomington-Indiana: The Mongolia Society.

Malov, S. Y. (1952). Yeniseyskaya Pismennost Tyurkov. Tekstı i Perevodı. MoskvaLeningrad: İzd. Akademii Nauk SSSR.

Maynagaşev, S. D. (1916). Jertvoprinoşenie Nebu u Beltir. Sbornik Muzeya Antropologii i Etnografii. Tipografiya Imperatorskoy Akademiya Nauk. 14(3), 93-102.

Medvedev, V. V. (2016). Predmety-Apotropei v Traditsiyah Çuvaşey. Nauçnıye Vedomosti Belgu (Belgorodskogo Gosudarstvennogo Universiteta). Seriya: İstoriya. Politologiya. 8(38), 144-149.

Nadelyayev, V. M. et al. (1969). Drevnetyurkskiy Slovar'. Leningrad: İnstitut Yazıkoznaniya, Akademiya Nauk SSSR.

Okladnikov, A. P. (1974). Petroglify Baykala: Pamyatniki drevney kultury narodov Sibiri. Novosibirsk: Nauka.

Okutan Davletov, N. (2021). Hakas Türklerinde Şamanizm ve Ölüm. İstanbul: Ötüken Neşriyat.

Ölmez, M. (2007). Tuwinischer Wortschatz mit alttürkischen und mongolischen Parallelen. (Tuvacanın Sözvarlığı, Eski Türkçe ve Moğolca Denkleriyle). Wiesbaden: Harrassowitz Verlag.

Pürbeyev, G. Ts. (2001). Bolşoy Akademiçeskiy Mongolsko-Russkiy Slovar I. Moskva: Academia.

Radloff, W. (1895). Die alttürkischen Inschriften der Mongolei. St. Petersburg: Buchdruckerei der kaiserlichen Akademie der Wissenschaften. 


\section{J(O)}

Rassadin, V. İ. (2003). Soyotsko-Buriatsko-Russkiy Slovar. Ulan Ude: İzd-vo Respublikanskaya Tipografiya.

Rassadin, V. İ. (2012). Yazık soyotov buryatii. Elista: İzd-vo KGU.

Rodionov, V. G. (2016). Çuvaşskie Kalendarnye Obryadovye Teksty (k Probleme Rekonstruktsii Osnovnyh Tsiklov). In Traditsionnaya Kultura Narodov Povoljya: Materialy III Vserossiyskoy Nauçno-Praktiçeskoy Konferentsii s Mejdunarodnym Uçastiem II (M-Ya.) (pp. 118-126). Kazan: İhlas.

Salmin, A. (1994). Narodnaya Obryadnost Çuvaşey. Çeboksarı: Çuvaşskiy gumanitarnyi institut.

Semenova, T. V. (2015). Osobennosti Obryadovogo Kalendarya Çuvaşey $v$ Etnokontaktnoy s Tatarami Zone. MAE RAN, Otdel etnografii vostoçnyh slavyan i narodov evropeyskoy çasti Rossii. (Yayımlanmamış Doktora Tezi)

Sevortyan, E. B. (2003). Etimologiçeskiy Slovar Tyurkskih Yazıkov: Obsschetyurkskie i Mejtyurkskie Osnovy Na Bukvu "L”, “M”, “N”, "P”, “S”. Moskva: Nauka.

Starostin, S. et al. (2003). Etymological Dictionary of the Altaic Languages I-III. LeidenBoston: Brill.

Subrakova, O. V. (2006). Hakassko-Russkiy Slovar' (Okolo 22 tıs. Slov). Novosibirsk: Nauka.

Şagdarov, L. D. \& Çeremisov, K. M. (2008). Buryadsko-Russkiy Slovar I-II. Ulan Ude: Respublikanskaya Tipografiya.

Tekin, T. (2014). Orhon Yazıtları. Ankara: Türk Dil Kurumu Yayınları.

Tsintius, V. İ. (1975). Sravnitelny Slovar Tunguso-Mançjurskih Yazıkov I-II. Moskva: Nauka.

Verbitskiy, V. (1884). Slovar Altayskago İ Aladagskago Nareçiy Tyurskago Yazıka. Kazan: Tipografiya V. M. Klyuçnikova.

Yadanova, K. V. (2013). Predaniya, legendy, byliçki telengitov dolinı Ere-Çuy. Red. Smirnov, Yu. I. Gorno Altaysk: Ni̇ Altaistiki im S. S. Surazakova. 